\title{
Effects of cyclic AMP and analogues on neurogenic transmission in the rat tail artery
}

\author{
Sylvin Ouedraogo, Jean-Claude Stoclet \& 'Bernard Bucher \\ Laboratoire de Pharmacologie Cellulaire et Moléculaire, C.N.R.S. URA 600, Université Louis Pasteur Strasbourg, B.P. 24, \\ 67401 Illkirch, France
}

1 The effects of two 8-substituted analogues of adenosine $3^{\prime}: 5^{\prime}$-cyclic monophosphate (cyclic AMP) were compared with those of forskolin and isoprenaline on $\left[{ }^{3} \mathrm{H}\right]$-noradrenaline release and vasoconstriction induced by electrical field stimulation ( 24 pulses at $0.4 \mathrm{~Hz}, 200 \mathrm{~mA}, 0.3 \mathrm{~ms}$ duration) in the rat tail artery, in the absence and in the presence of protein kinase inhibitors.

2 8-Bromo-adenosine 3':5'-cyclic monophosphate (8-bromo-cyclic AMP, 10-300 $\mu \mathrm{M}$ ), 8-(4-chlorophenylthio)-adenosine $3^{\prime}: 5^{\prime}$ cyclic monophosphate (8-pCPT-cyclic AMP, 3-300 $\left.\mu \mathrm{M}\right)$, forskolin $(0.3-10 \mu \mathrm{M})$ and isoprenaline $(1 \mathrm{nM}-1 \mu \mathrm{M})$ all concentration-dependently enhanced stimulation-induced $\left[{ }^{3} \mathrm{H}\right]$-noradrenaline release. The effect of cyclic AMP analogues was larger $(2.5$ fold at $300 \mu \mathrm{M})$ than those of cyclic AMP elevating drugs (1.6 fold at $10 \mu \mathrm{M}$ for forskolin and 1.5 fold at $30 \mathrm{nM}$ for isoprenaline).

3 At concentrations active at the prejunctional level, the four drugs had differential effects on stimulation-induced vasoconstriction, which was enhanced by the two cyclic AMP analogues, decreased by forskolin and not significantly altered by isoprenaline.

4 The $\left[{ }^{3} \mathrm{H}\right]$-noradrenaline release-enhancing effects of 8-bromo-cyclic AMP, forskolin and isoprenaline were significantly decreased by the cyclic AMP-dependent protein kinase (PKA) inhibitor $(\mathbf{N}-[2-((3-(4-$ bromophenyl)-2-propenyl)-amino)-ethyl]-5-isoquinolinesulphonamide, di-hydrochloride\} (H-89; $100 \mathrm{nM}$ ). By contrast they were unaffected by the cyclic GMP-dependent protein kinase (PKG) inhibitor, 8-bromo-guanosine 3':5'-cyclic monophosphorothioate, Rp-isomer (Rp-8-bromo-cyclic GMPS; $10 \mu \mathrm{M}$ ). At the same concentrations the PKA inhibitor attenuated only the nerve-induced vasoconstrictor responses obtained in the presence of 8-bromo-cyclic AMP, whereas the PKG inhibitor did not modify that obtained in the presence of 8-bromo-cyclic AMP or forskolin.

5 Exposure to the protein kinase $\mathrm{C}(\mathrm{PKC})$ activator, phorbol 12-myristate 13-acetate $(1 \mu \mathrm{M})$ enhanced nerve-evoked $\left[{ }^{3} \mathrm{H}\right]$-noradrenaline release, and this effect was decreased by the PKC inhibitor, 2-[1-(3dimethylaminopropyl)-indol-3-yl]-3-(-indol-3-yl)-maleimide (GF 109203X; $100 \mathrm{nM}$ ). However, the latter drug did not modify the enhancing effect of 8-bromo-cyclic AMP on $\left[{ }^{3} \mathrm{H}\right]$-noradrenaline release.

6 It is concluded that activation of cyclic AMP-dependent protein kinase is involved in the enhancing effect of cyclic AMP-elevating compounds on prejunctional release of noradrenaline. In addition the results provide no clear-cut evidence for a vasodilator role of PKA.

Keywords: Neurogenic vasoconstriction; noradrenaline release; cyclic AMP; forskolin; isoprenaline; cyclic AMP-dependent protein kinase; rat tail artery

\section{Introduction}

Adenosine $3^{\prime}: 5^{\prime}$-cyclic monophosphate (cyclic AMP) is an ubiquitous second messenger which is involved in the mediation of functional responses to a variety of hormones and neurotransmitters (reviewed by Beebe \& Corbin, 1986). In vascular smooth muscle cells, $\beta$-adrenoceptor stimulation or forskolin-induced activation by adenylyl cyclase are associated with an increase in the intracellular level of cyclic AMP (Kramer \& Hardman, 1980) and with relaxation, but the precise mechanism by which the cyclic nucleotide causes relaxation is not clear. Cyclic AMP is also operative in perivascular sympathetic nerve endings where it modulates neurotransmitter release. In support of this, we and others have reported that drugs which increase intracellular level of cyclic AMP facilitate electrically-induced noradrenaline release (Göthert \& Hentrich, 1984; Hentrich et al., 1985; Johnston \& Majewski, 1986; Costa \& Majewski, 1988; Bucher et al., 1990). However, although cyclic AMP is able to modulate noradrenaline release, it does not appear to play a role in the initiation of the release process itself (Bucher et al., 1990).

Until recently, all known actions of cyclic AMP or its derivatives were assumed to operate via activation of cyclic AMP-dependent protein kinase (PKA) (reviewed by Beebe \& Corbin, 1986). However, several recent studies addressed the

\footnotetext{
' Author for correspondence.
}

question whether cyclic AMP activation of PKA is the sole mechanism of cyclic AMP-dependent relaxation in smooth muscle. It has been shown by use of dibutyryl cyclic AMP and 8-bromo-cyclic AMP that a dissociation is observed between PKA activation and inhibition of contractions of rat vas deferens, suggesting that PKA is not responsible for the relaxant effects of these cyclic nucleotide analogues in this tissue (Hei et al., 1991). Other investigators reported that activation of the cyclic GMP-dependent protein kinase (PKG) rather than PKA was responsible for smooth muscle relaxation elicited by cyclic nucleotide analogues (Francis $\boldsymbol{e t}$ al., 1988). In addition, recent data support the view that activation of PKG by endogenously formed cyclic AMP may lead to a reduction of intracellular calcium and subsequent relaxation (Lincoln et al., 1990; Lincoln \& Cornwell, 1991). Interestingly, there is also evidence for the existence of other mechanisms involving a non-ATP-sensitive $\mathrm{K}^{+}$channel and possibly PKG in the mediation of smooth muscle relaxation elicited by cyclic AMP (Haynes et al., 1992).

The possible role for activation of either cyclic AMPdependent protein or cyclic GMP-dependent protein kinases in the regulation of both adrenergic neurotransmitter release and pressor responses has not been documented as yet in a vascular preparation. Therefore, the present study was designed to examine further the effects of cyclic AMP on vasoconstriction and noradrenaline release evoked by electrical field 
stimulation of the rat tail artery. Specifically, we investigated the influence of selective cyclic AMP- and cyclic GMPdependent protein kinase inhibitors on cyclic AMP-mediated effects.

\section{Methods}

\section{Measurement of $\left[{ }^{3} \mathrm{H}\right]$-noradrenaline release and vasoconstriction}

Male Wistar rats (12 weeks old) were killed by cervical dislocation and exsanguinated. A segment of about $2-2.5 \mathrm{~cm}$ of the proximal part of the ventral tail artery was dissected out as previously described (Illes et al., 1987; Bucher et al., $1992)$ and kept in oxygenated $\left(95 \% \mathrm{O}_{2} ; 5 \% \mathrm{CO}_{2}\right)$ physiological saline solution which contained (mM): $\mathrm{NaCl} 118, \mathrm{KCl}$ $4.8, \mathrm{CaCl}_{2} 2.5, \mathrm{KH}_{2} \mathrm{PO}_{4} 0.9, \mathrm{NaHCO}_{3} 25$, glucose 11 , ascorbic acid 0.3 and disodium EDTA 0.03. The two latter compounds were added to prevent the spontaneous oxidation of catecholamines. The arteries were cannulated at one end and preincubated for $1 \mathrm{~h}$ at $37^{\circ} \mathrm{C}$ in $1.5 \mathrm{ml}$ of medium of the same composition as above containing in addition $2.2 \mu \mathrm{M}(-)$ $\left[{ }^{3} \mathrm{H}\right]$-noradrenaline (specific activity $4.4 \mathrm{Ci} \mathrm{mmol}^{-1}$ ). The vessels were then washed three times with $20 \mathrm{ml}$ of $\left[{ }^{3} \mathrm{H}\right]$ noradrenaline-free medium, and suspended vertically, distal end uppermost, between two platinum wire electrodes. The gaps between the arteries and the electrodes were wide enough to allow undisturbed contraction or relaxation, yet sufficiently narrow to stimulate intramural nerve terminals effectively. The arteries were perfused via their proximal ends with medium by means of a roller pump with physiological saline solution containing $10 \mu \mathrm{M}$ cocaine in order to block the re-uptake of released $\left[{ }^{3} \mathrm{H}\right]$-noradrenaline. The perfusion rate was gradually increased from 0 to $2.2 \mathrm{ml} \mathrm{min}^{-1}$ during the first $10 \mathrm{~min}$ after suspension of the arterial segment between the two electrodes, and kept constant thereafter. The intraluminal perfusion pressure was determined with a pressure transducer and recorded on a pen recorder. Changes in perfusion pressure reflected changes in the resistance to flow, i.e. the degree of vasoconstriction. After having passed through the lumen, the perfusate was allowed to superfuse the advential surface of the vessel.

Experiments were done with arteries with functional endothelium unless otherwise stated. We have previously shown that electrical field stimlation did not produce endothelial damage (Bucher et al., 1992). In some arteries the endothelium was removed by passing a stream of $95 \% \mathrm{O}_{2}: 5 \% \mathrm{CO}_{2}$ through the lumen of the arterial segment at a pressure of $40-50 \mathrm{mmHg}$. The presence or absence of functional endothelium was verified by the presence or absence of relaxant responses to $10 \mu \mathrm{M}$ acetylcholine in noradrenaline $(1 \mu \mathrm{M})$ precontracted arteries (Bucher et al., 1992).

Each artery was subjected to six stimulation periods (24 pulses at $0.4 \mathrm{~Hz} ; 0.3 \mathrm{~ms} ; 200 \mathrm{~mA}$ ). The first stimulation period was applied after $96 \mathrm{~min}$ of perfusion and others followed at intervals of $16 \mathrm{~min}$. Collection of the perfusate/ superfusate started after $124 \mathrm{~min}$ of perfusion in 1, 2 or $6 \mathrm{~min}$ fractions. The stimulation period beginning at $128 \mathrm{~min}$ was termed $S_{1}$ and subsequent ones $S_{2}-S_{n}$. $S_{2}$ served as a control of stimulation-evoked tritium overflow (since the response was stable thereafter). The compounds were infused with a syringe pump into the perfusion stream at a rate of $17 \mu \mathrm{l}$ $\min ^{-1}$ for $8 \mathrm{~min}$ before either $S_{1}$ or $S_{3}$ and this was maintained until the end of the experiment when the arteries were solubilized in $1 \mathrm{ml}$ Soluene 100 (Packard Instrument, Paris, France). Tritium in the superfusate samples and arteries was measured by liquid scintillation spectrometry.

Tritium overflow was calculated as a fraction of the amount of tritium present in the tissue at the start of the respective collection period (fractional rate of outflow). For evaluation of stimulation-evoked tritium overflow, the difference between the overall tritium outflow during stimulation plus the following $4 \mathrm{~min}$ and the estimated basal outflow was calculated. The latter was assumed to change linearly from the $1 \mathrm{~min}$ collection period before the beginning of stimulation to that 5 to $6 \mathrm{~min}$ after the start of stimulation. The evoked tritium overflow was calculated as a percentage of the amount of tissue tritium at the beginning of the respective stimulation period.

\section{Data and statistical analysis}

In order to quantify drug effects on the evoked overflow or vasoconstriction, the ratio of the overflow or vasoconstriction evoked by the stimulation period in the presence of the drug at the fourth stimulation period $\left(\mathrm{S}_{4}\right)$ over the last evoked overflow or vasoconstriction preceding application of the drug $\left(\mathbf{S}_{2}\right)$ was determined. $\mathbf{S}_{4}$ was chosen because in preliminary experiments the maximal effect of each drug concentration was reached in these conditions. Drug effects on basal outflow were quantified in the following way: ratios of the fractional rate of outflow $\left(b_{n}\right)$ in the fraction collected immediately before the onset of the stimulation periods in the presence of drugs $\left(S_{3}-S_{4}\right)$ over the fractional rate of outflow in the fraction immediately before the onset of the last stimulation period preceding the application of any drug $\left(S_{2}\right)$ were calculated $\left(b_{n} / b_{2}\right)$.

Results are given as mean \pm s.e.mean where $n$ is the number of experiments. Comparisons were made by the Mann-Whitney test if the Kruskall-Wallis analysis indicated a significant difference between multiple groups. A probability level of 0.05 or less was considered significant. For multiple comparisons with the same control group, the limit of significance was divided by the number of comparisons according to Bonferroni (Wallenstein et al., 1980).

\section{Drugs}

The following compounds were used: (-)-noradrenaline hydrochloride, 8-bromo-adenosine $3^{\prime}: 5^{\prime}$-cyclic monophosphate (sodium salt; 8-bromo-cyclic AMP), 8-(4-chlorophenylthio)adenosine $3^{\prime}: 5^{\prime}$-cyclic monophosphate (sodium salt; 8-pCPTcyclic AMP), $( \pm)$-isoprenaline hydrochloride, forskolin, phorbol 12-myristate 13-acetate (PMA) (Sigma, L'Isle d'Abeau Chesnes, France); 8-bromo-guanosine $3^{\prime}: 5^{\prime}$-cyclic monophosphorothioate, Rp-isomer (sodium salt; Rp-8-bromo-cyclic GMPS; Biolog, Bremen, Germany); $\{\mathrm{N}-[2-((3-$-(4-bromophenyl) -2-propenyl)-amino)-ethyl] -5-isoquinolinesulphonamide, di-hydrochloride) (H-89), (Calbiochem, Meudon, France); 2-[1-(3-dimethylaminopropyl)-indol-3-yl]-3-(-indol-3yl)maleimide (GF 109203X; kindly donated by Glaxo, France). Stock solutions of all other substances were prepared with Milli-Q water (Millipore) and diluted as required with the exception of forskolin which was dissolved in $5 \%$ ethanol and of PMA and GF109203X which were dissolved in $10 \%$ dimethylsulphoxide (DMSO). Preliminary experiments showed that at the concentration used, ethanol and DMSO did not alter basal or electrically-evoked overflow of tritium or vasosconstriction (see also control values in the figures and table). (-)-[Ring-2,5,6- $\left.{ }^{3} \mathrm{H}\right]$-noradrenaline, specific activity $43.7-56.9 \mathrm{Ci} \mathrm{mmol}^{-1}$ (New. England Nuclear, Dreieich, Germany) was diluted with unlabelled (-)-noradrenaline hydrochloride in order to obtain a specific activity of $4.4 \mathrm{Ci} \mathrm{mmol}^{-1}$.

\section{Results}

\section{Effects of 8-substituted analogues of cyclic AMP, forskolin and isoprenaline}

In control as well as in treated arteries, tritium overflow and peak vasoconstriction evoked by the stimulation period $\mathbf{S}_{2}$ amounted respectively to $0.191 \pm 0.005 \%$ of tissue tritium and $100.7 \pm 2.4 \mathrm{mmHg}(n=158$; all appropriate experiments 
pooled). Under control conditions, stimulation-evoked overflow of tritium and vasoconstriction did not change upon subsequent stimulations, resulting thus in $S_{n} / S_{2}$ ratio which were not different from the unity but the fractional rate of basal tritium outflow declined with time (not shown). 8Bromo-cyclic AMP $(300 \mu \mathrm{M})$, increased the basal rate of tritium outflow compared to control experiments $\left(b_{4} / b_{2}\right.$ : $1.07 \pm 0.02 ; n=15$ and $0.98 \pm 0.02 ; n=18$, respectively; $P<$ $0.01)$. Infusion of the solvent or of the drugs did not cause any change in basal perfusion pressure (not shown).

8-Bromo-cyclic AMP $(10-300 \mu \mathrm{M}), 8$-pCTP-cyclic AMP $(3-300 \mu \mathrm{M})$, isoprenaline $(0.001-1 \mu \mathrm{M})$ and forskolin $(0.3-10$ $\mu \mathrm{M})$ produced concentration-dependent increases in electrically-evoked tritium overflow (Figures 1 and 2). However, although forskolin and isoprenaline were more potent than the 8-substituted cyclic AMP analogues, the maximal effect obtained with either $10 \mu \mathrm{M}$ forskolin $\left(\mathrm{S}_{4} / \mathrm{S}_{2}: 1.62 \pm 0.06\right.$; $n=8 ; P<0.01$ vs control) or isoprenaline $\left(\mathrm{S}_{4} / \mathrm{S}_{2}: 1.54 \pm 0.03\right.$; $n=6 ; P<0.05$ vs control) was significantly lower $(P<0.01)$ than the maximal effect obtained with either $300 \mu \mathrm{M} 8$ bromo-cyclic AMP $\left(\mathrm{S}_{4} / \mathrm{S}_{2}: 2.31 \pm 0.07 ; n=15 ; P<0.01\right.$ vs control ) or $300 \mu \mathrm{M}$ 8-pCPT-cyclic AMP $\left(\mathrm{S}_{4} / \mathrm{S}_{2}: 2.38 \pm 0.17\right.$; $n=5 ; P<0.05$ vs control). In addition, when isoprenaline (30 $\mathrm{nM})$ was added in combination with propranolol (30 nM), the facilitatory effect of the $\beta$-adrenoceptor agonist on the electrically-evoked release of tritium was significantly reduced $(P<0.01)$, the respective $S_{4} / S_{2}$ ratios in the absence and
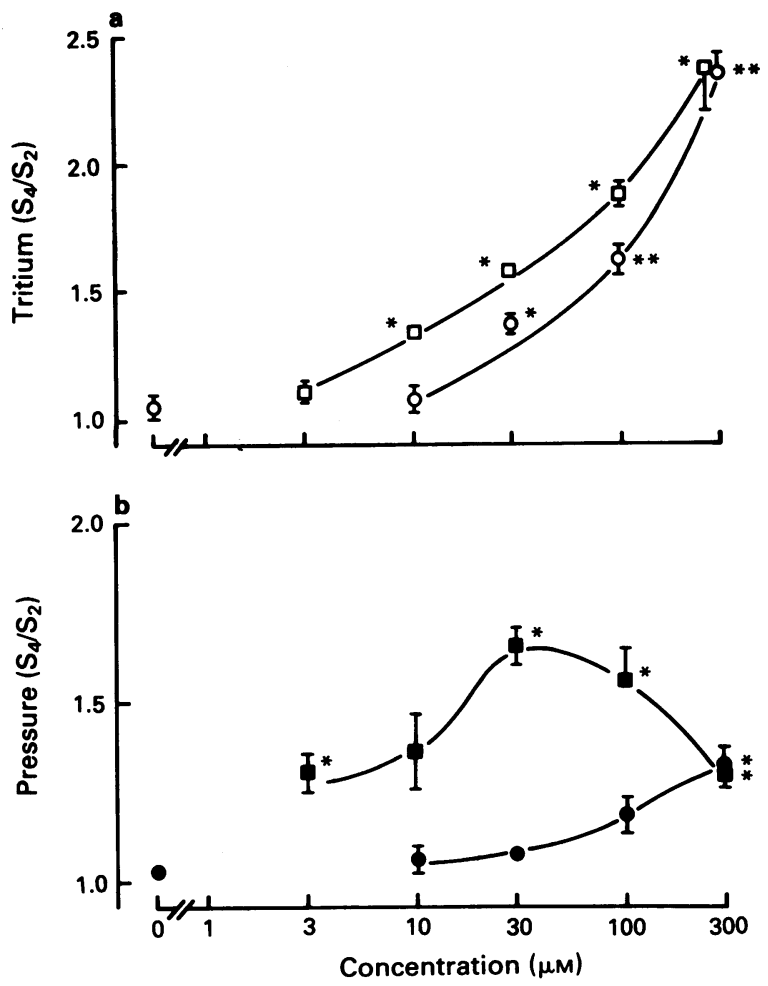

Figure 1 Effects of 8-bromo-cyclic AMP $(O, O)$ and of 8-pCPTcyclic AMP $(\square, \square)$ on electrically-evoked overflow of tritium (open symbols; a) and change in perfusion pressure (solid symbols; b) in rat tail arteries with functional endothelium preincubated with $\left[{ }^{3} \mathrm{H}\right]-$ noradrenaline. Four periods $\left(\mathrm{S}_{1}-\mathrm{S}_{4}\right)$ of field stimulation were delivered at intervals of $16 \mathrm{~min}(24$ pulses at $0.4 \mathrm{~Hz}, 200 \mathrm{~mA}, 0.3 \mathrm{~ms}$ duration). Each concentration of 8-bromo-cyclic AMP and of 8pCPT-cyclic AMP or the solvent (control group) was added $8 \mathrm{~min}$ before $S_{3}$ and maintained in the medium for the duration of the experiment. The effect of the drug is presented as the ratio of tritium overflow or change in perfusion pressure evoked by $S_{4}$ over that evoked by $S_{2}$. Each point represents the means \pm s.e.mean from 5-15 arteries. Significant difference from control: ${ }^{*} P<0,05$, $* * P<0.01$. presence of the $\beta$-antagonist being $1.54 \pm 0.03 ; n=6$ and $1.17 \pm 0.03 ; n=6$, respectively.

The stimulation-induced vasoconstriction was slightly increased by 8-bromo-cyclic AMP (Figure 1). However, the maximal effect of 8-bromo-cyclic AMP was less pronounced than that observed with 8-pCPT-cyclic AMP which reached its maximum at $30 \mu \mathrm{M}\left(\mathrm{S}_{4} / \mathrm{S}_{2}: 1.66 \pm 0.05 ; n=7 ; P<0.05\right.$ vs control) and decreased thereafter. In contrast, forskolin (3 $\mu \mathrm{M})$ induced a significant decrease in the stimulation-induced vasoconstriction (Figure 4) whereas isoprenaline had no effect. The $S_{4} / S_{2}$ ratio for $30 \mathrm{nM}$ isoprenaline was not significantly different from the corresponding control values $(1.18 \pm 0.07 ; n=6$ and $1.07 \pm 0.05 ; n=6$; respectively; $P>$ $0.05)$.

In arteries without functional endothelium, forskolin (1 $\mu \mathrm{M})$, produced the same relative enhancement of the tritium overflow $\left(\mathrm{S}_{4} / \mathrm{S}_{2}: 1.20 \pm 0.05 ; n=5\right)$ as it did in the presence of functional endothelium $\left(S_{4} / S_{2}: 1.25 \pm 0.03 ; n=7\right)$. The forskolin-mediated vasodilatation was slightly decreased in arteries without endothelium compared to the response observed in the presence of endothelium $\left(\mathrm{S}_{4} / \mathrm{S}_{2}: 0.62 \pm 0.08 ; n=5\right.$ and $0.47 \pm 0.05 ; n=7$; respectively; $P>0.05$ ).

\section{Influence of $\mathrm{H}-89$}

The enhancing effect of 8-bromo-cyclic AMP $(100 \mu \mathrm{M})$ on both electrically-induced vasoconstriction and tritium overflow $\left(S_{4} / S_{2}: 1.42 \pm 0.07\right.$ and $1.63 \pm 0.06 ; n=6$; respectively) was not significantly inhibited by $\mathrm{H}-8910 \mathrm{nM}\left(\mathrm{S}_{4} / \mathrm{S}_{2}: 1.39 \pm\right.$ 0.07 and $1.56 \pm 0.03 ; n=6$; respectively) and $30 \mathrm{nM}\left(\mathrm{S}_{4} / \mathrm{S}_{2}\right.$ : $1.38 \pm 0.12$ and $1.50 \pm 0.06 ; n=6$; respectively). However, a concentration of $100 \mathrm{nM}$ of the protein kinase A inhibitor maximally inhibited the 8-bromo-cyclic AMP-mediated effects on both electrically-evoked noradrenaline overflow and vasoconstriction (Figure 3). A concentration of $300 \mathrm{nM}$ of

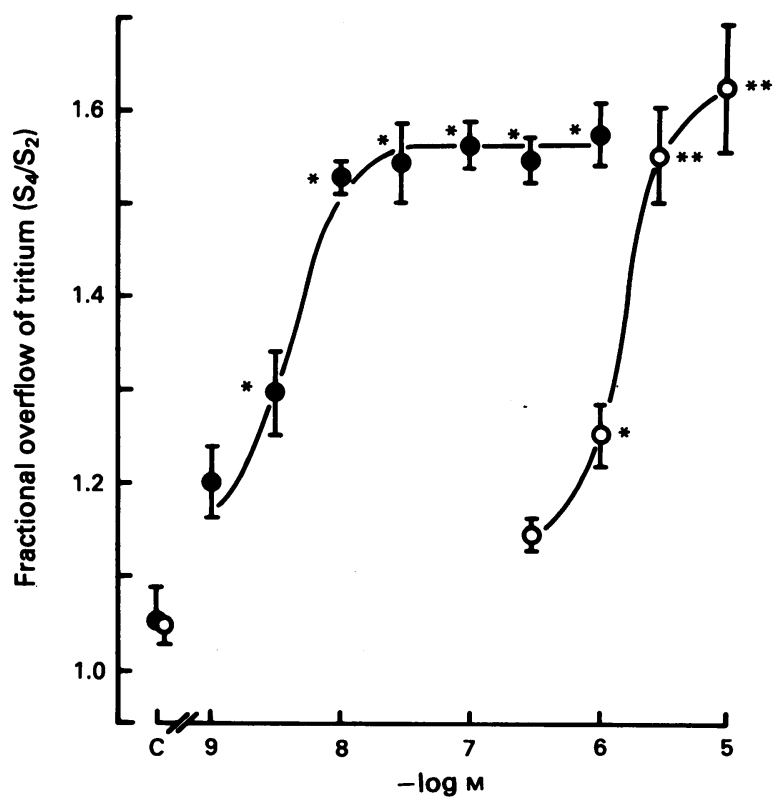

Figure 2 Concentration-dependent effects of isoprenaline (O) and forskolin $(\mathrm{O})$ on electrically-evoked overflow of tritium in rat tail arteries preincubated with $\left[{ }^{3} \mathrm{H}\right]$-noradrenaline. Four periods $\left(\mathrm{S}_{1}-\mathrm{S}_{4}\right)$ of field stimulation were delivered at intervals of 16 min (24 pulses at $0.4 \mathrm{~Hz}, 200 \mathrm{~mA}, 0.3 \mathrm{~ms}$ duration). Each concentration of isoprenaline or its solvent and forskolin or its solvent was added $8 \mathrm{~min}$ before $S_{3}$ and maintained in the medium for the duration of the experiment. The effects of the drugs are presented as the ratio of tritium overflow evoked by $S_{4}$ over that evoked by $S_{2}$. Each point represents the means \pm s.e.mean from six arteries. Significant difference from control: ${ }^{*} P<0.05,{ }^{* *} P<0.01$. 
H-89 produced a non-specific increase of the basal outflow of tritiated noradrenaline and the stimulation-induced overflow could not be satisfactorily estimated.

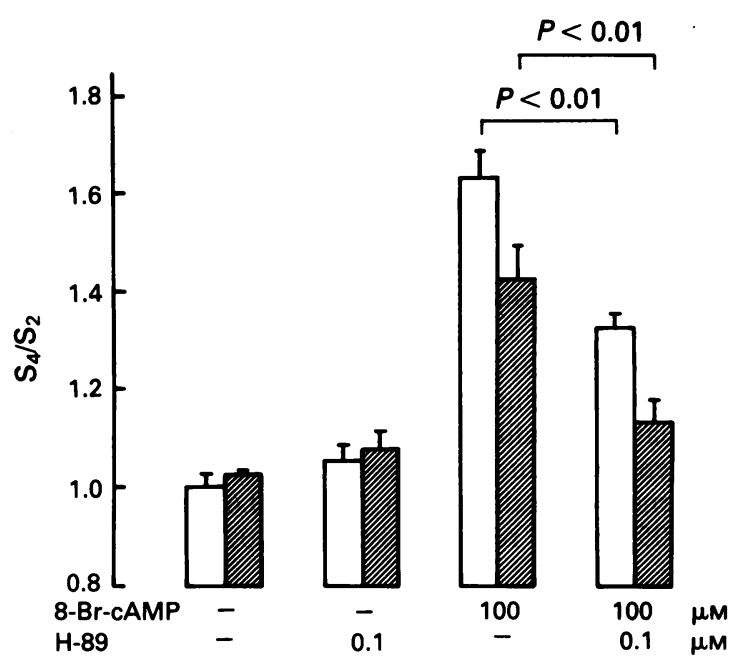

Figure 3 Effects of $\mathrm{H}-89$ and 8-bromo-cyclic AMP alone or in combination on electrically-evoked tritium overflow (open columns) and change in perfusion pressure (hatched columns) in rat tail arteries preincubated with $\left.{ }^{3} \mathrm{H}\right]$-noradrenaline. Four periods $\left(\mathrm{S}_{1}-\mathrm{S}_{4}\right)$ of field stimulation were delivered at intervals of $16 \mathrm{~min}$ ( 24 pulses at $0.4 \mathrm{~Hz}, 200 \mathrm{~mA}, 0.3 \mathrm{~ms}$ duration). H-89, 8-bromo-cyclic AMP or their solvents (control group) were added $8 \mathrm{~min}$ before $S_{3}$. All compounds were maintained in the medium for the duration of the experiment. The effect of the drugs are presented as the ratio of tritium overflow or change in perfusion pressure evoked by $S_{4}$ over that evoked by $S_{2}$. Each column represents the mean with s.e.mean from 6-7 arteries. The statistically significant differences between some values are indicated.

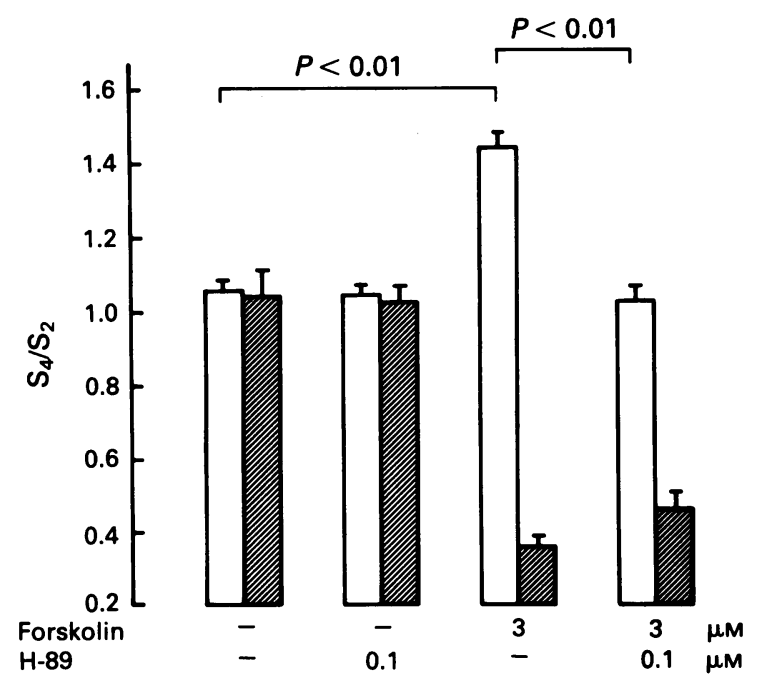

Figure 4 Effects of H-89 and forskolin alone or in combination on electrically-evoked tritium overflow (open columns) and change in perfusion pressure (hatched columns) in rat tail arteries preincubated with $\left[{ }^{3} \mathrm{H}\right]$-noradrenaline. Four periods $\left(\mathrm{S}_{1}-\mathrm{S}_{4}\right)$ of field stimulation were delivered at intervals of $16 \mathrm{~min}(24$ pulses at $0.4 \mathrm{~Hz}, 200 \mathrm{~mA}$, $0.3 \mathrm{~ms}$ duration). H-89 or its solvent (control group) was added $8 \mathrm{~min}$ before $S_{1}$. Forskolin or its solvent was added $8 \mathrm{~min}$ before $S_{3}$. All compounds were maintained in the medium for the duration of the experiment. The effects of the drugs are presented as the ratio of tritium overflow or change in perfusion pressure evoked by $\mathrm{S}_{4}$ over that evoked by $S_{2}$. Each column represents the mean with s.e.mean from 6-8 arteries. The statistically significant differences between some values are indicated.
By itself, $100 \mathrm{nM}$ of the cyclic AMP-dependent protein kinase inhibitor, $\mathrm{H}-89$, added to the perfusion/superfusion medium before $S_{1}$ or $S_{3}$ did not induce any modification in tritium overflow and vasoconstrictor response to periarterial nerve stimulation (Figures 3, 4 and 5). As shown in Figure 4, the enhancing effect of $3 \mu \mathrm{M}$ forskolin on electrical fieldelicited tritium overflow was significantly decreased in the presence of $0.1 \mu \mathrm{M} \mathrm{H}-89$ whereas stimulation-induced vasoconstriction was unchanged. Also, H-89 (100 nM) significantly attenuated the facilitatory effect of isoprenaline (30 nM) on tritium overflow without effecting the stimulationinduced vasoconstriction (Figure 5).

\section{Influence of Rp-8-bromo-cyclic GMPS}

A stable membrane permeant competitive inhibitor of cyclic GMP-dependent protein kinase, Rp-8-bromo-cyclic GMPS, was used in order to determine whether a PKG is involved in the effects of the cell permeant analogue 8-bromo-cyclic AMP or the adenylyl cyclase activator forskolin. Rp-8bromo-cyclic GMPS $(10 \mu \mathrm{M})$ added before $S_{1}$ or $S_{3}$ had no significant effect by itself or on the electrically-evoked tritium overflow and vasoconstriction (Figures 6 and 7). Furthermore, it did not modify the effects of 8-bromo-cyclic AMP $(100 \mu \mathrm{M})$ (Figure 6) and forskolin $(1 \mu \mathrm{M})$ (Figure 7) on the electrically-evoked tritium overflow and vasoconstriction.

\section{Influence of protein kinase $C$ activators and inhibitors}

The addition of PMA $(1 \mu \mathrm{M})$ before $S_{3}$ resulted in an increase in both the stimulation-induced overflow of tritium and resulting vasoconstriction (Table 1). A potent protein kinase $\mathrm{C}$ inhibitor, GF $109203 \mathrm{X}(100 \mathrm{nM})$, produced no significant effect by itself but it significantly attenuated the enhancing effects of PMA $(1 \mu \mathrm{M})$ on the stimulation-evoked noradrenaline release (Table 1). By contrast, the solvent of both GF $109203 \mathrm{X}$ and PMA (10\% DMSO) was without effect by

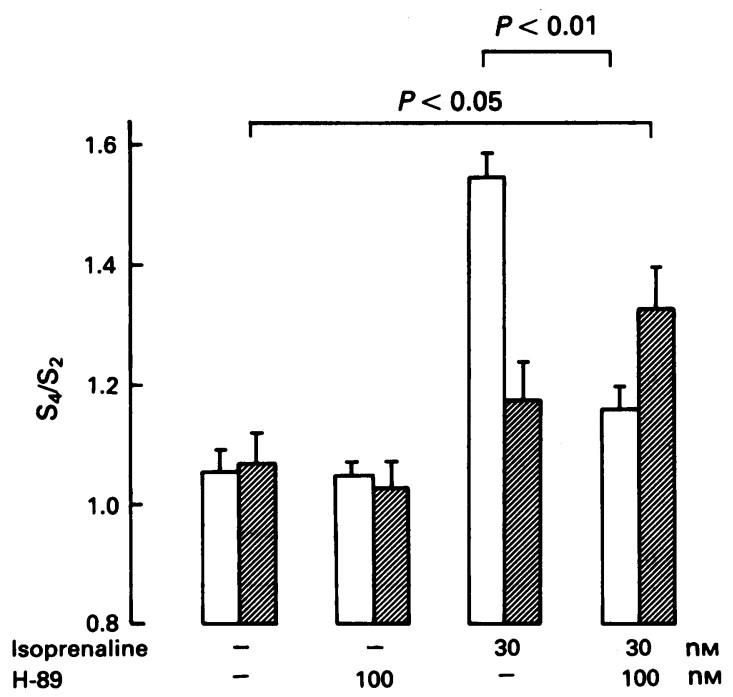

Figure 5 Effects of $\mathrm{H}-89$ and isoprenaline alone or in combination on electrically-evoked tritium overflow (open columns) and change in perfusion pressure (hatched columns) in rat tail arteries preincubated with $\left[{ }^{3} \mathbf{H}\right]$-noradrenaline. Four periods $\left(S_{1}-S_{4}\right)$ of field stimulation were delivered at intervals of $16 \mathrm{~min}(24$ pulses at $0.4 \mathrm{~Hz}, 200 \mathrm{~mA}$, 0.3 ms duration). H-89 or its solvent (control group) was added $8 \mathrm{~min}$ before $S_{1}$. Isoprenaline or its solvent was added $8 \mathrm{~min}$ before $S_{3}$. All compounds were maintained in the medium for the duration of the experiment. The effects of the drugs are presented as the ratio of tritium overflow or change in perfusion pressure evoked by $S_{4}$ over that evoked by $S_{2}$. Each column represents the mean with s.e.mean from 6 arteries. The statistically significant differences between some values are indicated. 
itself. GF $109203 \mathrm{X}(100 \mathrm{nM})$ had no effect on the facilitatory effect of 8-bromo-cyclic AMP $(100 \mu \mathrm{M})$ on electrical fieldevoked tritium overflow and vasoconstriction (Table 1), showing no evidence for the involvement of PKC in the effects of cyclic AMP.

\section{Discussion}

The results of the present investigation provide additional evidence supporting the view that cyclic AMP increases the electrically-evoked overflow of $\left[{ }^{3} \mathrm{H}\right]$-noradrenaline from the rat tail artery. In addition, they clearly show that the prejunctional enhancing effects of cyclic AMP-elevating drugs and cyclic AMP analogue on electrical-field induced $\left[{ }^{3} \mathbf{H}\right]-$ noradrenaline release were reduced by a PKA inhibitor, but were unaffected by either a PKG or a PKC inhibitor.

The cyclic AMP-mediated enhancement of electricallystimulated neurotransmitter release observed here is in good agreement with previous results obtained in the same vessel (Bucher et al., 1990) and in other vascular preparations (Göthert \& Hentrich, 1984; Hentrich et al., 1985; Johnston \& Majewski, 1986; Costa \& Majewski, 1988). The two adenylyl cyclase stimulating drugs, isoprenaline and forskolin, acted with the potency that could be expected from their effects on cyclic AMP production (Seamon \& Daly, 1986). Their maximal effects (1.6 fold stimulation) were not different from each other, but were lower than the effects of high concentra-

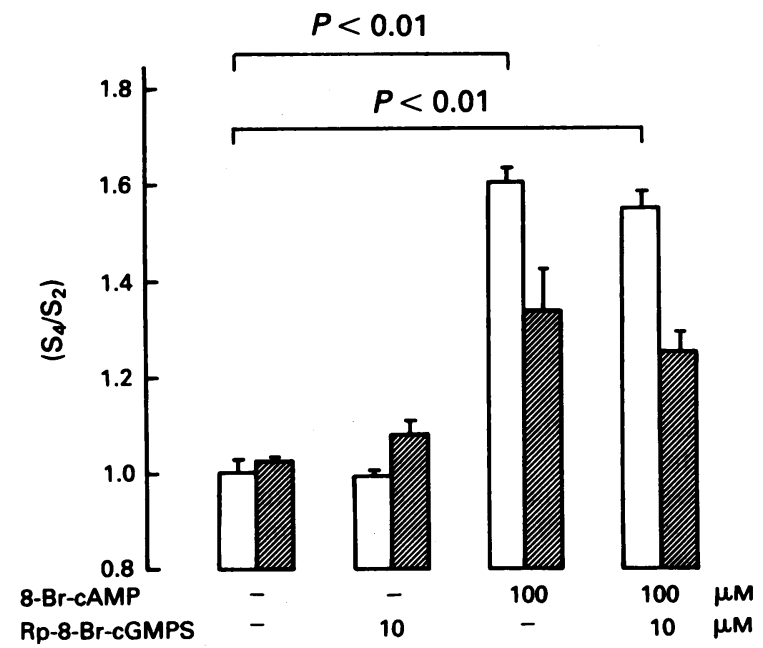

Figure 6 Effects of Rp-8-bromo-cyclic GMPS and 8-bromo-cyclic AMP alone or in combination on electrically-evoked tritium overflow (open columns) and change in perfusion pressure (hatched columns) in rat tail arteries preincubated with $\left[{ }^{3} \mathbf{H}\right]$-noradrenaline. Four periods $\left(S_{1}-S_{4}\right)$ of field stimulation were delivered at intervals of $16 \mathrm{~min}$ ( 24 pulses at $0.4 \mathrm{~Hz}, 200 \mathrm{~mA}, 0.3 \mathrm{~ms}$ duration). Rp-8bromo-cyclic GMPS, 8-bromo-cyclic AMP or their solvents (control group) were added $8 \mathrm{~min}$ before $S_{3}$. All compounds were maintained in the medium for the duration of the experiment. The effect of the drugs are presented as the ratio of tritium overflow or change in perfusion pressure evoked by $\mathrm{S}_{4}$ over that evoked by $\mathrm{S}_{2}$. Each column represents the mean with s.e.mean from 4-7 arteries. The statistically significant differences between some values are indicated.

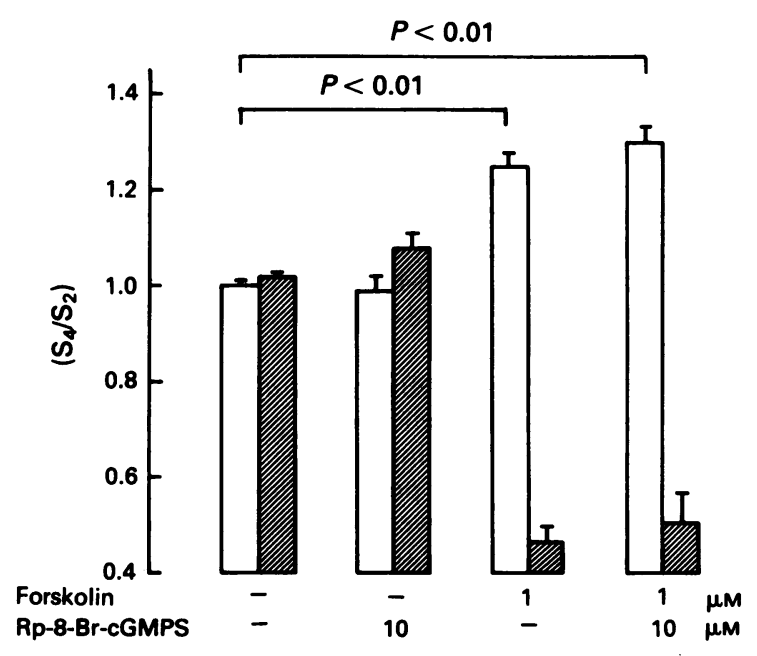

Figure 7 Effects of Rp-8-bromo-cyclic GMPS and forskolin alone or in combination on electrically-evoked tritium overflow (open columns) and change in perfusion pressure (hatched columns) in rat tail arteries preincubated with $\left[{ }^{3} \mathrm{H}\right]$-noradrenaline. Four periods $\left(\mathrm{S}_{1}-\mathrm{S}_{4}\right)$ of field stimulation were delivered at intervals of $16 \mathrm{~min}(24$ pulses at $0.4 \mathrm{~Hz}, 200 \mathrm{~mA}, 0.3 \mathrm{~ms}$ duration). Rp-8-bromo-cyclic GMPS, or its solvent (control group) was added $8 \mathrm{~min}$ before $S_{1}$. Forskolin or its solvent was added $8 \mathrm{~min}$ before $S_{3}$. All compounds were maintained in the medium for the duration of the experiment. The effects of the drugs are presented as the ratio of tritium overflow or change in perfusion pressure evoked by $S_{4}$ over that evoked by $S_{2}$. Each column represents the mean with s.e.mean from 4-7 arteries. The statistically significant differences between some values are indicated.

Table 1 Effects of phorbol 12-myristate 13-acetate (PMA) and 8-bromo-cyclic AMP alone or in combination with GF 109203X on electrically-evoked tritium overflow and change in perfusion pressure in rat tail arteries

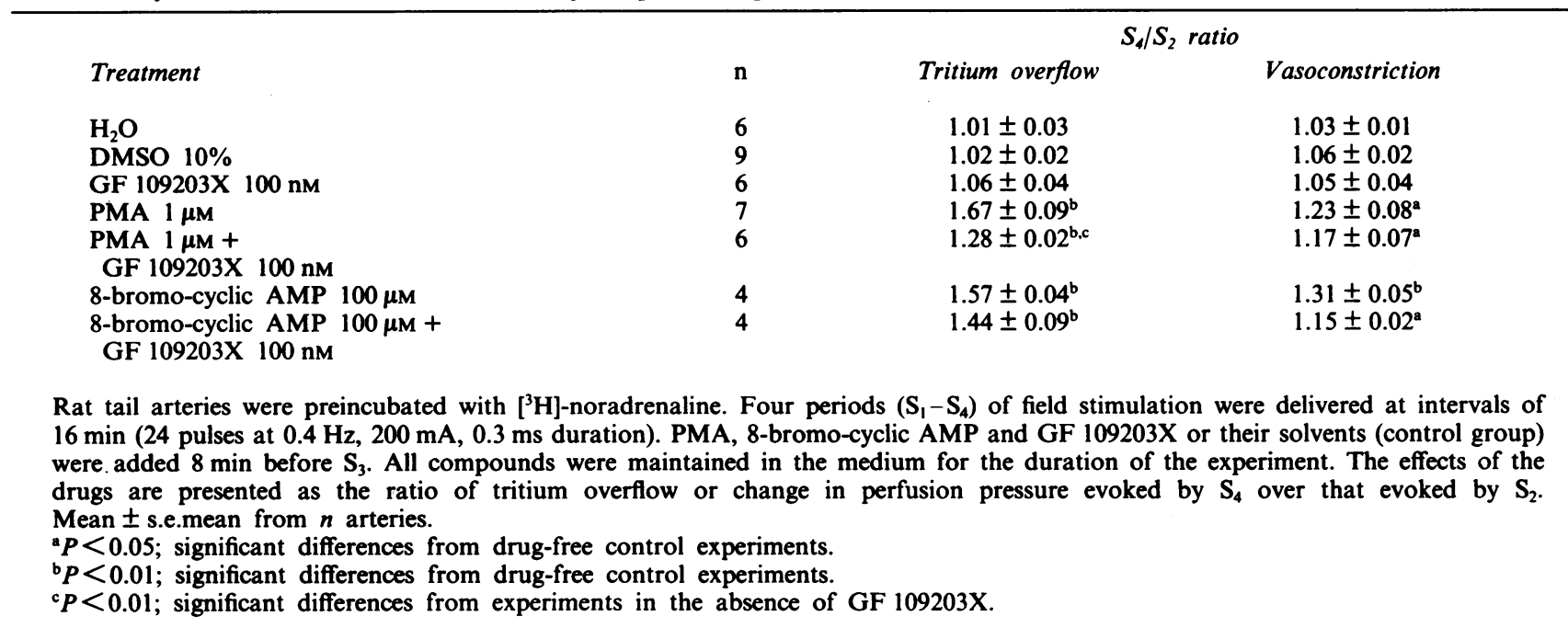


tions $(300 \mu \mathrm{M})$ of the two cyclic AMP analogues (2.5 fold stimulation), suggesting that maximal stimulation of adenylyl cyclase by either isoprenaline or forskolin could not produce maximal enhancement of noradrenaline release. As expected from its higher lipophilicity resulting in good membrane permeability (Sandberg et al., 1991), 8-pCPT-cyclic AMP acted at lower concentrations than 8-bromo-cyclic AMP.

In the current study, H-89, a selective PKA inhibitor (Chijiwa et al., 1990) by itself did not alter spontaneous and electrical stimulation-induced release of neurotransmitter. However, it reduced the enhancement of $\left[{ }^{3} \mathrm{H}\right]$-noradrenaline release by forskolin, isoprenaline and 8-bromo-cyclic AMP. Taken together these results indicate that following stimulation by exogenous agents, PKA enhances noradrenaline release, but this pathway appears not to be endogenously active in the absence of such agents. Furthermore, neither $\mathrm{Rp}$-8-bromo-cyclic GMPS, an 8-bromo derivative of $\mathrm{Rp}$ cyclic GMPS, which is a membrane permeant and metabolically stable selective inhibitor of PKG (Butt et al., 1990), nor GF 109203X, a potent and selective inhibitor of PKC (Toullec et al., 1991), had any effect on stimulation-induced noradrenaline release or vasoconstriction. Neither poor membrane permeability nor the use of inadequate concentrations of these drugs could explain their lack of effects: in the same experimental conditions GF $109203 \mathrm{X}$ was able to antagonize PMA (this study) and Rp-8-bromo-cyclic GMPS was able to attenuate significantly the 8-bromo-cyclic GMP-induced relaxation (data not shown).

As previously discussed (Bucher et al., 1990), the effects of drugs on vasoconstriction elicited by periarterial nerve stimulation are more difficult to interpret, since they may represent the net result of pre- and post-junctional actions. Although the rat tail artery is endowed with postjunctional $\beta$-adrenoceptors (Bao et al., 1990; Rajanayagam et al., 1990), isoprenaline had no significant effect on neurogenic vasoconstriction. Although there was a prejunctional $\beta$-adrenoceptor-mediated increase in noradrenaline release from nerve terminals, any postjunctional $\alpha$-adrenoceptor-mediated response was probably inhibited via the postjunctional $\beta$-adrenoceptor-mediated relaxant effect of isoprenaline. In spite of increasing neurotransmitter release, forskolin produced a concentration-dependent vasodilatation, whereas both of the cyclic AMP analogues potentiated nerve-induced vasoconstriction. These differences may reflect differences in the sensitivity of the preand postjunctional target systems and/or differences in the ability of the drugs to diffuse into the respective cellular compartments. Additionally, 8-pCPT-cyclic AMP, although increasing stimulation-induced vasoconstriction at concentrations up to $30 \mu \mathrm{M}$, decreased it at higher concentrations. It has been shown recently that 8-pCPT-cyclic AMP shows little selectivity for the activation of PKA over PKG (Sandberg et al., 1991) and that it is also a potent inhibitor of the cyclic GMP-specific phosphodiesterase (PDE $\mathrm{V}_{\mathrm{A}}$ ) (Connolly et al., 1992). This provides further reasons to interpret with caution the biphasic effect on stimulation-induced vasoconstriction observed in the present experiments. It is therefore possible that the observed effects with higher concentrations of this cyclic AMP derivative might be secondary to PDE $V_{A}$ inhibition which in turn increases the intracellular level of cyclic GMP and induces vasorelaxation. In these conditions, due to the complex pharmacological effects of this derivative and its poor selectivity for PKA the effects of protein kinase inhibitors were only investigated with the 8-bromo-analogue.

The attenuation by $\mathrm{H}-89$ of the enhancing effect of 8- bromo-cyclic AMP on stimulation-induced vasoconstriction could result from the above discussed inhibition of the prejunctional effect of the cyclic AMP analogue on noradrenaline release. The findings that, in spite of antagonizing the cyclic AMP-induced increase in neurotransmitter release, $\mathbf{H}$ 89 did not modify vasoconstrictor responses obtained in the presence of isoprenaline and forskolin, would imply that both pre- and postjunctional effects of these drugs were decreased by the PKA inhibitor. However, the persistence of a marked depressor effect of forskolin on vasoconstriction, in the presence of $\mathrm{H}-89$, suggests that a mechanism other than PKA activation may be involved. It has previously been shown that a non-cyclic AMP-mediated relaxant effect of forskolin due to a direct effect on $\mathrm{K}^{+}$channels (Hoshi et al., 1988; Ertl \& Nawrath, 1989) is not likely since 1,9-dideoxyforskolin was unable to decrease the stimulation-elicited vasoconstriction (Bucher et al., 1990). Other mechanisms, perhaps involving adenylyl cyclase activation or not, cannot be excluded. The results obtained here with forskolin are consistent with recent observations showing that $\mathrm{Rp}$-cyclic AMPS (Rp diastereoisomer of adenosine $3^{\prime}: 5^{\prime}$-cyclic monophosphorothioate), a PKA inhibitor had no effect on forskolin-mediated vasodilatation (Haynes et al., 1992). In addition, the present finding showing that the PKG inhibitor, Rp-8bromo-cyclic GMPS, did not alter forskolin-induced inhibition of the vessel contraction and had no effect on vasoconstriction elicited in the presence of 8-bromo-cyclic AMP do not support a role of PKG in these drugs actions.

It is clear from our previous research that neither the endothelium nor the L-arginine-NO pathway is implicated in the modulation of stimulation-induced noradrenaline release from postganglionic nerve endings in the rat tail artery (Bucher et al., 1992). However, an important question that arises from the present study relates to the possible influence of the endothelium on the cyclic AMP-dependent effects on vasoconstriction. In the present study and in previous work (Bucher et al., 1990) only forskolin produced a clear-cut concentration-dependent decrease in the stimulation-induced vasoconstriction. This inhibitory effect is considered to occur via an increase in cyclic AMP within the smooth muscle cells (Kukovetz et al., 1981). The fact that in the present study endothelium removal failed to alter significantly forskolininduced relaxation suggests that the vascular effects of the adenylyl cyclase activator occurred independently of the endothelium. A similar conclusion has been reached by others (Kamata et al., 1989; Graves \& Poston, 1993).

Reciprocal interactions between the cyclic AMP/PKA pathway and PKC had been suggested in a variety of tissues (Rozengurt et al., 1987; Naghshineh et al., 1989; Gorin et al., 1990; Anderson et al., 1991; Mazancourt et al., 1991). In the rat tail artery, a role for PKC in the prejunctional release of noradrenaline has recently been suggested (Bucher et al., 1991). Consistent with this suggestion, it was found here that PMA enhanced electrical field-induced noradrenaline release. However, inhibition of PKC did not modify the effect of 8-bromo-cyclic AMP at this level, providing no evidence for a role of PKC in cyclic AMP-mediated modulation of neurotransmitter release.

Altogether, the current study shows that, in the rat tail artery, the prejunctional cyclic AMP-mediated facilitation of stimulated noradrenaline release involves the activation of cyclic AMP-dependent protein kinase but provides no substantial evidence for a postjunctional vasodilator role of the kinase.

\section{References}

ANDERSON, R.J., BRECKON, R. \& COLSTON, D. (1991). Regulation by forskolin of cyclic AMP phosphodiesterase and protein kinase C activity in LLC-PK cells. Biochem. J., 279, 23-27.

BAO, J.X.. ERIKSSON, I.E. \& STJÄRNE, I. (1990). Neurotransmitter and pre- and post-junctional receptors involved in the vasoconstrictor response to sympathetic nerve stimulation in the rat tail artery. Acta Physiol. Scand., 140, 467-479.
BEEBE, S.J. \& CORBIN, J.D. (1986). Cyclic nucleotide-dependent protein kinases. In The Enzymes, vol. XVII. ed. Boyer, P.D. \& Krebs, E.G., pp. 43-111. New York: Academic Press.

BUCHER, B., NEUbURGeR, J. \& ILlES, P. (1991). Protein kinase C and $\alpha_{2}$-adrenoceptor-mediated inhibition of noradrenaline release from the rat tail artery. J. Cardiovasc. Pharmacol., 17, 913-915. 
BUCHER, B., OUEDRAOGO, S., TSCHÖPL, M., PAYA, D. \& STOCLET, J.-C. (1992). Role of the L-arginine-NO pathway and of cyclic GMP in electrical field-induced noradrenaline release and vasoconstriction in the rat tail artery. Br. J. Pharmacol., 107, 976-982.

BUCHER, B., PAIN, L., STOCLET, J.-C. \& ILLES, P. (1990). Role of cyclic AMP in the prejunctional $\alpha_{2}$-adrenoceptor modulation of noradrenaline release from the rat tail artery. Naunyn-Schmied. Arch. Pharmacol., 342, 640-649.

BUTT, E., VAN BEMMELEN, M., FISCHER, L., WALTER, U. \& JASTORFF, B. (1990). Inhibition of CGMP-dependent protein kinase by (Rp)-guanosine 3',5'-monophosphorothioates. FEBS Lett., 263, 47-50.

CHIJIWA, T., MiSHIMA, A., HAGIWARA, M., SANO, M., HAYASHI, K., INOUE, T., NAITO, K., TOSHIOKA, T. \& HIDAKI, H. (1990). Inhibition of forskolin-induced neurite outgrowth and protein phosphorylation by a newly synthesized selective inhibitor of cyclic AMP-dependent protein kinase, N-[2-(p-bromocinnamylamino)ethyl]-5-isoquinolinesulfonamide (H-89), of PC12D pheochromocytoma cells. J. Biol. Chem., 265, 5267-5272.

CONNOLLY, B.J., WILLITS, P.B., WARRINGTON, B.H. \& MURRAY, K.J. (1992). 8-(4-Chlorophenyl)thio-cyclic AMP is a potent inhibitor of the cyclic GMP-specific phosphodiesterase (PDE $V_{\mathbf{A}}$ ). Biochem. Pharmacol., 44, 2303-2306.

COSTA, M. \& MAJEWSKI, H. (1988). Facilitation of noradrenaline release from sympathetic nerves through activation of ACTH receptors, $\beta$-adrenoceptors and angiotensin II receptors. $\mathrm{Br} . \mathrm{J}$. Pharmacol., 95, 993-1001.

ERTL, R. \& NAWRATH, H. (1989). Cyclic AMP-independent membrane effects of forskolin in atrial and ventricular heart and aortic smooth muscle preparations from guinea pigs. NaunynSchmied. Arch. Pharmacol., 339, R52.

FRANCIS, S.H., NOBLETT, B.D., TODD, B.W., WELLS, J.N. \& CORBIN, J.D. (1988). Relaxation of vascular and tracheal smooth muscle by cyclic nucleotide analogs that preferentially activate purified cGMP-dependent protein kinase. Mol. Pharmacol., 34, 506-517.

GORIN, E., TAI, L.R., HONEYMAN, T.W. \& GOODMAN, H.M. (1990). Evidence for a role of protein kinase $\mathrm{C}$ in the stimulation of lipolysis by growth hormone and isoproterenol. Endocrinology, 126, 2973-2982.

GÖTHERT, M. \& HENTRICH, F. (1984). Role of cAMP for regulation of impulse-evoked noradrenaline release from the rabbit pulmonary artery and its possible relationship to presynaptic ACTH receptors. Naunyn-Schmied. Arch. Pharmacol., 328, 127-137.

GRAVES, J. \& POSTON, L. (1993). $\beta$-Adrenoceptor agonist mediated relaxation of rat isolated resistance arteries: a role for the endothelium and nitric oxide. Br. J. Pharmacol., 108, 631-637.

HAYNES Jr, J., ROBINSON, J., SAUNDERS, L., TAYLOR, A.E. \& STRADA, S.J. (1992). Role of cAMP-dependent protein kinase in cAMP-mediated vasodilation. Am. J. Physiol., 262, H511- H516.

HEI, Y.-J., MACDONELL, K.L., MCNEILL, J.H. \& DIAMOND, J. (1991). Lack of correlation between activation of cyclic AMP-dependent protein kinase and inhibition of vas deferens by cyclic AMP analogs. Mol. Pharmacol., 39, 233-238.

HENTRICH, F., GÖTHERT, M. \& GRESCHUCHNA, D. (1985). Involvement of cAMP in modulation of noradrenaline release in the human pulmonary artery. Naunyn-Schmied Arch. Pharmacol., 330, 245-247.

HOSHI, T., GARBER, S.S. \& ALDRICH, R.W. (1988). Effect of forskolin on voltage-gated $\mathrm{K}^{+}$channels is independent of adenylate cyclase activation. Science, 240, 1652-1655.
ILLES, P., BETTERMANN, R., BROD, I. \& BUCHER, B. (1987). $\beta$ Endorphin-sensitive opioid receptors in the rat tail artery. Naunyn-Schmied. Arch. Pharmacol., 335, 420-427.

JOHNSTON, H. \& MAJEWSKI, H. (1986). Prejunctional $\beta$-adrenoceptors in rabbit pulmonary artery and mouse atria; the effect of $\alpha$-adrenoceptor blockade and phosphodiesterase inhibition. $\mathrm{Br} . J$. Pharmacol., 87, 553-562.

KAMATA, K., MIYATA, N. \& KASUYA, Y. (1989). Involvement of endothelial cells in relaxation and contraction responses to isoproterenol in naive and streptozotocin-induced diabetic rats. $J$. Pharmacol. Exp. Ther., 249, 890-894.

KRAMER, G.L. \& HARDMAN, J.G. (1980). Cyclic nucleotides and blood vessel contraction. In Handbook of Physiology: The Cardiovascular System. II.- Vascular Smooth Muscle. ed. Bohr, D.F., Somlyo, A.P. \& Sparks, H.P. pp. 179-199. Bethesda: American Physiological Society.

KUKOVETZ, W.R., POCH, G. \& HOLZMANN, S. (1981). Cyclic nucleotides and relaxation of vascular smooth muscle. In Vasodilatation. ed. Vanhoutte, P.M. \& Leusen, I. pp. 339-353. New York: Raven Press.

LINCOLN, T.M. \& CORNWELL, T.L. (1991). Towards an understanding of the mechanism of action of cyclic AMP and cyclic GMP in smooth muscle relaxation. Blood Vessels, 28, 129-137.

LINCOLN, T.M., CORNWELL, T.L. \& TAYLOR, A.E. (1990). CGMPdependent protein kinase mediates the reduction of $\mathrm{Ca}^{2+}$ by cAMP in vascular smooth muscle cells. Am. J. Physiol., 258 , C399-C407.

DE MAZANCOURT, P., DARIMONT, C., GIOT, J. \& GIUDICELLI, Y. (1991). Differential modulation of the adenylate cyclase/cyclic AMP stimulatory pathway by protein kinase $C$ activation in rat adipose tissue and isolated fat cells. Biochem. Pharmacol., 42, $1791-1797$.

NAGHSHINEH, S., NOGUCHI, M., HUANG, K.P. \& LONDOS, C. (1989). Activation of adipocyte adenylate cyclase by protein kinase C. J. Biol. Chem., 261, 14534-14538.

RAJANAYAGAM, M.A.S., MEDGETT, I.C. \& RAND, M.J. (1990). Vasoconstrictor responses of rat tail artery to sympathetic nerve stimulation contain a component due to activation of postjunctional $\beta$ - or $\alpha_{2}$-adrenoceptors. Eur. J. Pharmacol., 177, 35-41.

ROZENGURT, E., MURAY, M, ZACHARI, I. \& COLLINS, M. (1987). Protein kinase $C$ activation enhances cAMP accumulation in Swiss 3T3 cells: inhibition by pertussis toxin. Proc. Natl. Acad. Sci. U.S.A., 84, 2282-2286.

SANDBERG, M., BUTT, E., NOLTE, C., FISCHER, L., HALBRUGGE, M., BELTMAN, J., JAHNSEN, T., GENIESER, H.-G., JARSTORFF, B. \& WALTER, U. (1991). Characterization of Sp-5,6-dichloro-1- $\beta$ D-ribofuranosyl-benzimidazole-3', 5'-monophosphorothioate (Sp5,6-DCl-cBiMPS) as a potent and specific activator of cyclicAMP-dependent protein kinase in cell extracts and intact cells. Biochem. J., 279, $521-527$.

SEAMON, K.B. \& DALY, J.W. (1986). Forskolin: its biological and chemical properties. Adv. Cyclic Nucleotide Protein Phosphorylation Res., 20, 1-150.

TOULlEC, D., PIANETTI, P., COSTE, H., BELlEVERGUE, P., GRANDPERRET, T., AJAKANE, M., BAUDET, V., BOISSIN, P., BOURSIER, E., LORIOLLE, F., DUHAMEL, L., CHARON, D. \& KIRILOVSKY, J. (1991). The bisindolylmaleimide GF $109203 \mathrm{X}$ is a potent and selective inhibitor of protein kinase C. J. Biol. Chem., 266, $15771-15781$.

WALLENSTEIN, S., ZUCKER, C.L. \& FLEISS, J.L. (1980). Some statistical methods used in circulation research. Circ. Res., 47, 1-9.

(Received July 12, 1993

Revised October 11, 1993

Accepted October 22, 1993) 